\title{
0 Gorillaz é uma banda "de mentira"? Uma discussão sobre o papel das bandas virtuais na música massiva ${ }^{1}$
}

\section{Ariane Diniz Holzbach}

\section{Resumo}

Este artigo pretende fazer uma discussão sobre 0 papel das bandas virtuais na música massiva da atualidade, a fim de entender como uma banda que não existe no "plano real" faz parte da indústria do entretenimento com a mesma legitimidade que bandas com integrantes de carne e osso. Para isso, serão analisadas a performance ao vivo e as estratégias de surgimento e consolidação da banda virtual Gorillaz, uma das mais impactantes do gênero das últimas décadas. Para terem legitimidade e conseguirem se enquadrar no cenário musical, essas bandas tratam de maneira bastante particular elementos essenciais da experiência musical, desconstruindo parte de seus conceitos.

\section{Palavras-chave}

Banda virtual. Música massiva.

Identidade visual. Performance.

\section{Ariane Diniz Holzbach I aridiniz@gmail.com}

Mestre em Comunicação pela Universidade Federal Fluminense (2008), graduada em Comunicação Social (Jornalismo) pela Universidade Federal de Pernambuco (2004) e, atualmente, doutoranda do Programa de Pós-graduação em Comunicação da UFF. Tem experiência nas áreas de jornalismo impresso e televisão, já desenvolveu pesquisa em Lingüística, Estudos Culturais e Comunicação e Política. Atualmente, desenvolve pesquisa em audiovisual e música popular massiva, com ênfase em videoclipe. É professora da Universidade Gama Filho, trabalha na Contracampo, do PPGCOM-UFF, participa do LabCult (Laboratório de Pesquisa em Culturas Urbanas, Lazer e Tecnologias, coordenado pela professora Simone Maria Andrade Pereira de Sá) e é editora-chefe do Clipestesia (www.clipestesia.com.br), feito em parceria com alunos dos cursos de Estudos Culturais e Mídia, Jornalismo e Produção Cultural, da UFF.

\section{Introdução}

No final da década de 1950, a televisão e a indústria fonográfica começaram a se surpreender com "Alvin and the Chipmunks", que no Brasil virou "Alvin e os Esquilos", um trio de esquilos roqueiros criados pelo produtor Rostom Sipan Bagdasarian que até hoje faz sucesso entre o público infantil. Os esquilos já gravaram mais de 40 álbuns e ganharam cinco Grammys dos 13 em que concorreram. Ao longo de seus mais de 50 anos de carreira ininterrupta, o grupo protagonizou um seriado de TV homônimo, cantou com gente como Michael Jackson, protagonizou diversos filmes, assinou contrato com a major Universal, tem mais de 15 DVDs e vários singles que ficaram semanas nas paradas norte-americanas. Rostom, o criador, morreu em 1979, mas 20 anos depois sua invenção continua ocupando importante posição na indústria do entretenimento. A longevidade da carreira dos três esquilos roqueiros é rara no campo musical, mas não o estilo que o grupo integra. Há dezenas (talvez centenas) de bandas ao redor do mundo que não são feitas com pessoas de carne e osso, 
mas que movimentam uma parcela significativa da indústria da música, as bandas virtuais.

Bandas virtuais são grupos formados por personagens animados que existem apenas no plano virtual, são inteiramente construídos. Uma de suas características mais marcantes é que em geral elas seguem a mesma lógica de produção, circulação e consumo das bandas não virtuais de música massiva, mas são, em essência, diferentes. Como qualquer grupo musical, elas criam álbuns, músicas e singles que são lançados nos meios de comunicação, têm integrantes mais ou menos fixos que tocam os instrumentos e cantam, fazem shows ao vivo e se relacionam com a mídia para divulgar seu trabalho por meio de entrevistas, sites na internet, releases para a imprensa... Entretanto, seus integrantes são deliberadamente inventados e toda a relação que se constrói em torno da música, da banda e do público gira em torno dessa invenção. 0 circuito de consumo da música das bandas virtuais sabe desde 0 início que produtores e músicos "de verdade" criam os sons, as composições e as vozes dos personagens, mas ocultar essa informação faz parte da experiência de consumo da música e da legitimação desse tipo de banda. Elas, então, acabam sendo tratadas pelo público da mesma forma que as bandas com integrantes de carne e osso.

As bandas virtuais não são um fenômeno recente, como os esquilos roqueiros atestam, mas ganharam novo fôlego com a consolidação da internet e com as novas possibilidades que o ciberespaço vem proporcionando. Mais do que nunca, elas podem construir e reforçar sua imagem através de espaços na rede que não necessitam de um corpo para fazerem sentido, apenas de uma identidade, e ao mesmo tempo tensionam a relação da música massiva enquanto produto, na medida em que as bandas virtuais tratam de uma forma bastante particular elementos fundamentais da experiência musical como performance e identidade visual. Nesse sentido, a proposta deste artigo é fazer uma discussão em torno do papel das bandas virtuais na música massiva da atualidade, com destaque para o papel da internet nesse processo, a fim de entender como uma banda que não existe no plano real faz parte da indústria do entretenimento com a mesma legitimidade que bandas "de verdade", e que estratégias são construídas para que isso ocorra. Para tanto, serão analisadas a performance ao vivo (apesar de virtual, o grupo faz apresentações ao vivo, como será descrito adiante) e as estratégias de surgimento e consolidação do Gorillaz, criado em 1998 e ainda em atividade, uma das mais impactantes bandas virtuais das últimas décadas - segundo a gravadora, até agora o grupo vendeu 17 milhões de discos - com destaque para os videoclipes e sites feitos para o grupo. Como se trata de uma banda que foi solidificando seu 
espaço durante o processo de crescimento e consolidação das novas tecnologias, sobretudo da internet, a partir dela é possível perceber como esse novo cenário tem atuado na concepção e atuação das bandas virtuais e que papel elas desempenham na atualidade.

\section{Gorillaz, uma experiência tanto visual quanto musical}

Nos estudos sobre audiovisual e música dos últimos anos, há um esforço no sentido de valorizar e compreender o papel que o som desempenha na cultura contemporânea. Encabeçada pelos Sound Studies, essa corrente tem lutado para que o som seja analisado com a mesma legitimidade que o elemento visual, este tido como um campo vastamente explorado há décadas em muitas correntes de pensamento. Nesse esforço em legitimar o campo sonoro e mesmo em entender melhor de que maneira o som atua nos elementos culturais, muitas vezes ambos - som e imagem acabam aparecendo como se fossem antagônicos, independentes por definição.

De um lado, nos estudos do audiovisual, o som comumente é tratado como um elemento à parte da imagem, com características próprias e frequentemente tendo um papel apenas complementar ao que os olhos veem. Berchmans, nesse sentido, faz uma ampla análise da música no cinema, tendo como base o filme hollywoodiano, e afirma que a música apenas " [...] auxilia a narrativa, seus personagens, seu ritmo, suas texturas, sua linguagem, seus requisitos dramáticos" (BERCHMANS, 2006, p. 20). Goodwin (1993), por sua vez, no seu clássico estudo sobre videoclipe, critica a maior parte das correntes de estudos do audiovisual devido à importância que dão à imagem em detrimento do som e, em particular, da música. Uma das grandes críticas do autor recai sobre os estudos referentes à MTV que Kaplan (1993) realizou. De acordo com ele, a autora deu tanta importância à imagem que não parecia analisar um canal musical. Indo além, Goodwin afirma que os videoclipes devem ser analisados primordialmente tendo em vista a relação que travam com a música popular massiva ${ }^{2}$.

De outro lado, no campo sonoro, Sterne (2006), no seu famoso estudo sobre a reprodução do som ao longo da história, afirma que, em detrimento da importância concedida à imagem no Ocidente, é preciso dar atenção ao som. 0 autor descreve como a sociedade foi acostumada a perceber 0 mundo a partir da visão e como a imagem ocupa a maior parte das preocupações de

Goodwin utiliza a expressão "popular music", que em português seria "música popular". Mas como esta expressão tem uma conotação diferente nos estudos sobre música no Brasil, ligada ao folclore e não ao consumo massivo e à mediação feita pelos meios de comunicação, optou-se por traduzir o termo usando a expressão mais frequentemente utilizada em português por teóricos da área: música popular massiva. 
escolas literárias, de estudos de cinema, da semiótica, do pós-estruturalismo, da arquitetura e da comunicação, entre outros campos. Opondo-se a essa tradição, mas sem negar a importância do visual, Sterne propõe prestar atenção nos sons modernos e em como as práticas sociais foram influenciadas em boa medida pelo que se ouve. Na mesma linha de Sterne, Pinch e Bijsterveld (2004) fazem um apanhado da tradição dos Sound Studies e afirmam que o mundo científico e tecnológico se desenvolveu num ambiente visual. Também se opondo ao protagonismo imagético na cultura contemporânea, os dois propõem que, para além do "paradigma visual", é preciso levar em conta que o mundo é composto também por outros sentidos, e a partir daí analisam o papel que 0 som desempenha sobretudo no mundo moderno.

Levados em boa medida pelo aspecto material, já que tecnicamente som e imagem são de fato produzidos separadamente, e pela clara predominância do aspecto visual na análise de elementos culturais modernos feita por muitos especialistas por várias décadas, muitos autores se posicionam a favor do som numa tentativa de lutar contra uma tradição unilateral de interpretar o mundo. Mas ao fazerem isso, por vezes acabam reforçando uma dicotomia que, como tal, despreza justamente um dos lados dessa relação: 0 aspecto visual. Essa separação é útil para uma melhor compreensão do som enquanto objeto de estudo, mas não dá conta da análise da música produzida pelas bandas virtuais. Isso porque esse gênero já é criado a partir de uma referência visual totalmente interdependente em relação à música que realizam. As bandas virtuais não ganhariam sentido e forma não fosse a construção visual que as integra.

Essa interdependência entre som e imagem é bastante explícita quando se analisam os videoclipes do Gorillaz. 0 videoclipe, como pontua Allan (1990) ao comparar o gênero com os musicais, é um audiovisual que só pode ser eficientemente compreendido se levados em conta, na mesma medida, 0 visual e 0 imagético. Apesar de 0 videoclipe ser estruturado a partir de uma música pré-existente, ele só toma forma quando ganha imagens. $\mathrm{E}$ estas, por sua vez, não fariam sentido se não acompanhassem a música. No caso do Gorillaz, os videoclipes servem de propaganda para a banda, cumprindo uma de suas principais funções, mas prioritariamente ajudam a dar forma e identidade ao grupo, como será visto a seguir.

\subsection{Gorillaz, imagens, identidade e videoclipes}

0 Gorillaz surgiu em 1998 como projeto paralelo de Damon Albarn, vocalista e líder da banda inglesa de rock Blur, e do designer e cartunista Jamie Christopher Hewlett. Os dois amigos afirmaram que estavam assistindo à MTV e decidiram fazer algo diferente $^{3}$. Criaram quatro personagens animados - 2D, Murdoc, Noodle e Russel -, 
convidaram alguns músicos e, em 2000, foi lançado pela Parlophone, pertencente à EMI, um EP com quatro músicas. Era uma forma de testar a popularidade que a experiência alcançaria. Desse trabalho surgiu um videoclipe, Tomorrow comes today ${ }^{4}$, e, simultaneamente, foi criado o site da banda, ambos com características singulares. A música e seu videoclipe foram divulgados em poucos meios de comunicação do Reino Unido e faziam uma rápida apresentação do Gorillaz e de seus integrantes. No início do videoclipe, que foi dirigido por um dos criadores, Jamie Hewlett, aparece em letras vermelhas o nome da banda, uma estratégia de apresentação que vai ser utilizada em muitos trabalhos subsequentes, o que é raro em videoclipes de bandas não virtuais, mas que, no caso de um grupo sem referencial concreto, concede a ele unidade e familiaridade. Posteriormente, cada integrante vai aparecendo separadamente em meio a fotografias e desenhos de ruas e bairros de Londres, o que localiza espacialmente a banda. Sempre em primeiro plano, os integrantes aparecem tocando seus instrumentos e interpretando a música, enquanto a letra brinca com a definição de virtual que define a própria banda: "Não pense que eu não estou neste mundo/ A câmera não me deixará ir / E 0 veredicto não gosta da nossa alma / 0 digital não vai me deixar ir (tradução nossa)" 0 site oficial ${ }^{6}$ da banda, por sua vez, no lugar de conter informações sobre o grupo, na época de lançamento desse videoclipe simulava um estúdio de gravação, o Kong Studios, que também seria a casa dos integrantes. Atualmente 0 site tem informações institucionais sobre a banda, e outro site foi criado para abrigar os integrantes do Gorillaz, como será visto adiante, mas no início era mais um espaço para legitimar os integrantes do que para divulgar seus trabalhos. No lugar de serem tratados apenas como músicos, apareciam no site como personagens mais amplos, pois era necessário formatar bem suas características. Quando o site foi lançado e durante os primeiros anos de sucesso, cada integrante tinha seu "quarto" no site e espaços coletivos onde treinavam, criavam músicas e tinham momentos de lazer. Para suprir a necessidade de divulgar informações profissionais, foi criado um site complementar, o Fans.Gorillaz ${ }^{7}$, mais parecido com um site tradicional de banda.

Entrevista concedida à Q TV. Disponível em: <http://www.youtube.com/watch?v=eHOHITloXHl>. Acesso em: 11 abr. 2010.

Ver 0 clipe em <http://www.youtube.com/watch?v=loTV8_veiEY>. Acesso em: 11 abr. 2010.

"Don't think l'm not all in this world / The camera won't let me go /And the verdict doesn't love our soul / The digital won't let me go".

Disponível em : <http://gorillaz.com/>. Acesso em: 11 abr. 2010.

Disponível em: <http://fans.gorillaz.com/>. Acesso em: 11 abr. 2010. 
Como o resultado do trabalho inicial foi bem recebido, a gravadora e os criadores do Gorillaz elaboraram um álbum inteiro e partiram para uma ampla estratégia de divulgação. 0 primeiro single verdadeiramente comercial, Clint Eastwood, foi lançado em 2001 e fez muito sucesso, inclusive no Brasil. A estratégia de lançamento foi muito importante para legitimar a banda virtual. A música começou a tocar nas rádios e ninguém sabia ao certo que grupo era aquele, visto que o EP havia sido restritamente divulgado, o que aumentou a atenção dedicada por parte da audiência ao grupo. Pouco tempo depois, o mistério foi desfeito: a MTV passou a veicular 0 videoclipe da canção ${ }^{8}$, no qual eram cuidadosamente apresentados os quatro integrantes animados para o grande público.

Dirigido novamente por Jamie Hewlett e agora também por Pete Candeland, o videoclipe é todo feito em animação, e muitas imagens são inspiradas no faroeste The Good, the Bad and the Ugly, estrelado em 1966 por Clint Eastwood. A música, apesar de não fazer referências ao ator norte-americano, tem um sample feito a partir da canção-tema do filme. Depois de um grito retirado do longa e de o nome da banda aparecer em vermelho, os personagens vão sendo focados um a um. A audiência que

Figura 1 - Os integrantes do Gorillaz: na frente, a guitarrista Noodle e, de camisa verde, o vocalista 2D. Atrás, 0 baterista Russel e, com cigarro na mão, o baixista Murdoc. Fonte: Wikipédia. Disponível em: <http://en.wikipedia.org/wiki/Gorillaz>. Acesso em: 11 abr. 2010.

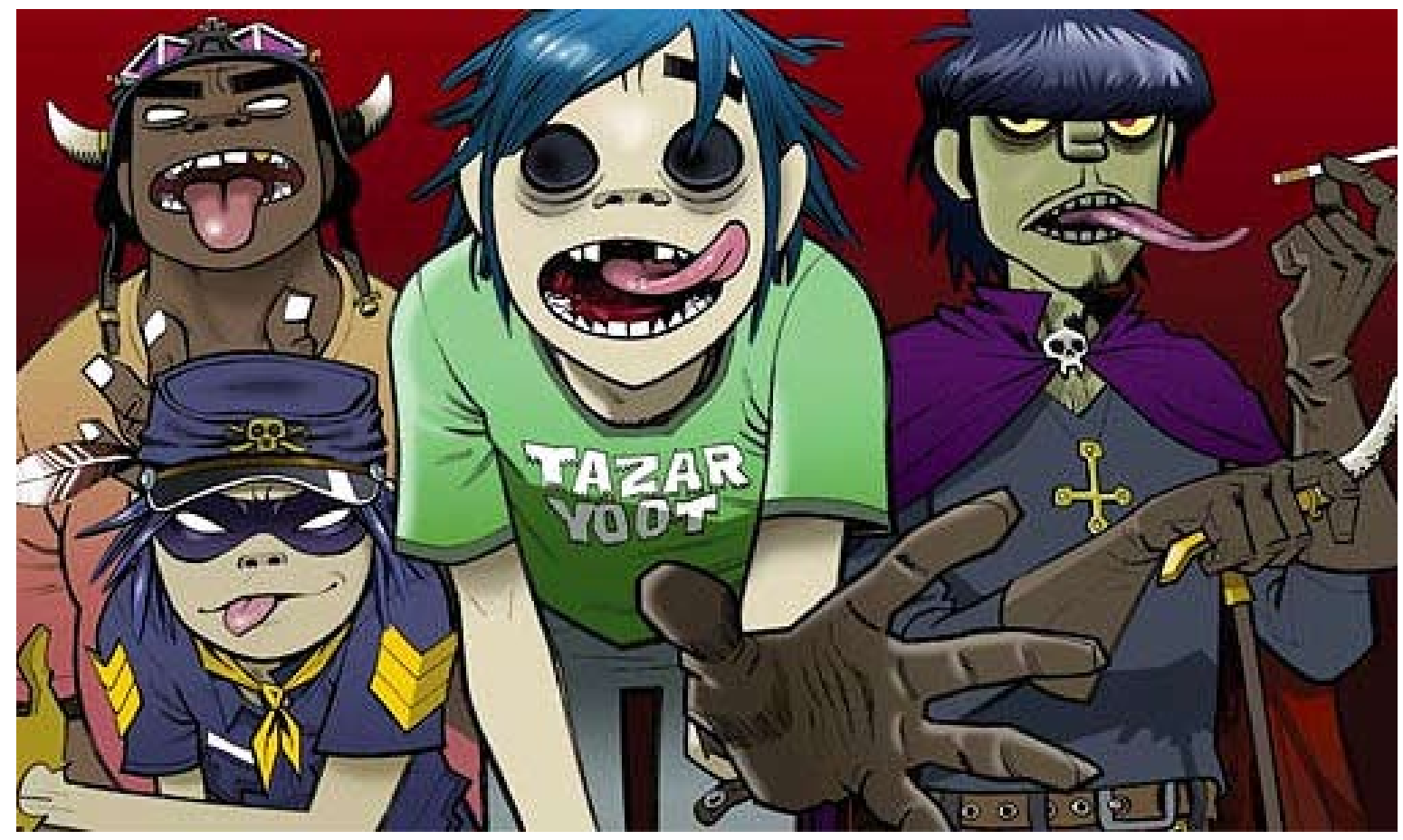


ainda não os conhece já pode tirar muitas conclusões, mas terá informações mais completas se tiver acesso aos sites do grupo e às várias entrevistas e matérias que já estavam sendo publicadas sobre eles.

\section{0 baixista Murdoc Niccals é o primeiro a} aparecer, tem um ar soturno, um olho preto e outro vermelho. Na história inventada para 0 grupo e amplamente divulgada em entrevistas simultaneamente à veiculação desse videoclipe, descobre-se rapidamente que Murdoc é um personagem invejoso e com um humor sempre irônico. Ele é o criador do Gorillaz e o mais velho, 43 anos atualmente, tem gostos estranhos e não gosta do vocalista 2D, pois por ele ser feio e esquisito teria perdido a posição de vocalista para alguém mais atraente. Seguindo a ordem de apresentação do videoclipe, $\log _{0}$ atrás dele aparece 0 baterista problemático Russel Hobbs. Loiro e grandão, cresceu no bairro americano do Brooklyn e, ainda pequeno, foi possuído por um demônio. Depois de exorcizado, mudou de escola e então começou a ser introduzido no mundo hip hop, uma das grandes influências musicais do Gorillaz. Quando tentava levar uma vida normal, tomou parte em um acidente de carro em que muitos de seus amigos morreram. Os espíritos de todos eles entraram no corpo de Russel, incluindo o espírito de seu melhor amigo Del, e estão lá até hoje. Este amigo aparece nesse videoclipe e em alguns outros, sempre em azul, como se fosse um fantasma saído literalmente da cabeça de Russel, cantando os trechos em estilo rap das músicas. Por causa desses acontecimentos, Russel frequentemente é calado e estranho em entrevistas e outras aparições. Seguindo a apresentação que 0 videoclipe proporciona, 0 terceiro integrante a aparecer é a guitarrista Noodle. Ela nasceu em 1990 em Osaka, Japão, e é a mais nova do grupo. Começou a fazer parte da equipe com apenas dez anos, depois de ser encontrada a partir de um anúncio que o Gorillaz fez na importante magazine europeia NME - New Musical Express -, que existe de fato, porque a então guitarrista do grupo e namorada de 2D, Paula Cracker, foi demitida após ser flagrada mantendo relações sexuais com o baixista Murdoc. Quando aportou na Inglaterra, a única palavra que a japonesa sabia em inglês era "noodle", que virou seu pseudônimo. Por fim, é a vez de o videoclipe apresentar o vocalista 2D ou Stuart Pot. De cabelos roxos e postura eternamente curvada, tem esse apelido por causa dos dois dentes da frente que lhe faltam desde que, aos 19 anos, foi atropelado propositalmente por Murdoc. Nesse acidente, 2D teve várias fraturas na face, ficou algum tempo em estado catatônico e, depois de voltar ao normal, foi acometido por uma eterna dor de cabeça, o que faz com que esteja sempre mal-humorado.

Essa complexa teia construída em torno dos integrantes do Gorillaz responde a uma necessidade intrínseca à música popular 
massiva. De acordo com Janotti (2007, p.

8), esse gênero constrói sua base a partir de reconhecimentos que estão "atrelados diretamente à posse de capitais culturais que envolvem a produção musical, a narrativa biográfica, genealogias, referências e distinções que englobam elementos mercadológicos e musicais". Tendo em vista que 0 Gorillaz surge sem um capital simbólico atrelado à sua imagem, faz-se necessário criar um conjunto de características e ações que permitam à banda ser reconhecida no circuito musical ao qual se insere. Dentro dos vários gêneros de música massiva ${ }^{9}, 0$ grupo é rotulado como uma banda de rock alternativo; sub-gênero comumente relacionado a elementos como autenticidade e subversividade em relação ao rock mainstream (BANNISTER, 2006). As complexas características dos personagens, algumas bastante negativas, atuam diretamente na construção de uma imagem descolada, diferente, alternativa do grupo.

Essa imagem vai de encontro ao conceito de identidade contemporânea que vigora em muitos estudos, especialmente os relacionados ao conceito de pós-moderno. Desde meados do século XX, diversos autores destacam as diferenças no modo de viver das sociedades contemporâneas quando comparadas aos tempos mais antigos (HARVEY, 1992, JAMESON, 1996, HALL, 2002, SANTAELLA, 2000). Uma das mais fortes características desses novos tempos reside no que Hall, seguindo os estudos de Laclau (1990), chama de deslocamento ou descentramanto do sujeito, um sujeito formado por identidades fluidas, múltiplas, fragmentadas. Mas no caso do Gorillaz, a identidade construída é, ao contrário, fixa, única, cartesiana. Para que as características de cada integrante sejam facilmente compreendidas e fixadas pelo público, uma identidade linear é desenhada em torno deles.

Essa identidade tem também outra característica muito importante: para existir no mundo concreto, 0 Gorillaz precisa fixar sua imagem através dos videoclipes e do site oficial, ou seja, a identidade do grupo é essencialmente formada no processo de mediação. Boorstin (1992) baseia boa parte de sua teoria no conceito cunhado por ele de pseudo-evento, que seriam eventos não espontâneos criados prioritariamente, embora não unicamente, para serem descritos, mediados pelos meios de comunicação. Apesar de serem "enganosos" e "falsos" num primeiro momento, os pseudo-eventos acabam naturalizados, tornando-se "verdadeiros" justamente por causa da atenção e credibilidade concedida pelos meios de comunicação. Sendo um pseudoevento, 0 Gorillaz atua constantemente nesse processo de naturalização. Em 2005, quando os integrantes já eram conhecidos, o grupo lançou seu segundo álbum, "Demon Days", seguido por uma nova e ainda mais violenta estratégia de 
divulgação. Um das músicas de trabalho, Feel Good Inc, foi feita em parceria com o grupo de hip hop De La Soul, surgido em 1987 e bastante tradicional. 0 videoclipe ${ }^{10}$ mostra os integrantes do Gorillaz em uma ilha flutuante tocando e cantando a música, sendo que com imagens relacionadas à identidade já criada em torno deles. Murdoc, por exemplo, o baixista esquisito, aparece tocando seu baixo numa cama, sem camisa, ao lado de duas mulheres nuas que 0 acariciam, e ele, contudo, não esboça qualquer reação. Já o vocalista 2D canta "feel good" - "sentir-se bem" - com o olhar baixo e melancólico 0 tempo inteiro, como se estivesse com a eterna enxaqueca e nunca se sentisse realmente bem. Mas ao lado do Gorillaz, o videoclipe expõe um elemento concreto: os integrantes do De La Soul aparecem sempre que estão cantando um trecho da música, o que ajuda a aproximar a banda virtual de uma banda real, ajudando a naturalizar assim a existência do Gorillaz.

Ainda nesse processo de naturalização, ao lançarem o segundo álbum, novos elementos virtuais foram criados. 0 Kong Studios perdeu parte de sua função e um novo site oficial surgiu, 0 Gorillaz.It ${ }^{11}$. Além de uma infinidade de fotos e informações sobre biografias, videoclipes e entrevistas, há agora um link dedicado a curtos episódios animados que ajudam a dar vida aos personagens. Carregados de humor, cada episódio tem no máximo 90 segundos, um formato enxuto que faz muito sucesso em sites como Youtube, e segue temáticas relacionadas à identidade já criada em torno dos personagens. Além desses episódios, foram criados uma biografia autorizada do grupo, Rise of The Ogre ("0 Crescimento do 0gro"), e um documentário contando a história do surgimento da banda, o Bananaz.

\section{Gorillaz e a performance musical}

Até o momento, problematizou-se a formação da identidade da banda virtual Gorillaz, mas destacando-se apenas elementos audiovisuais e virtuais - os videoclipes e sites na internet -, ou seja, elementos em que não há necessidade de o grupo aparecer de forma corporificada. Mas a legitimação de uma banda de música massiva passa de forma expressiva pela performance musical ao vivo. Vejamos como o Gorillaz trata esse elemento.

Frith (1996) aponta que a performance ao vivo dos músicos - a maneira como se portam no palco e interagem com a audiência nos shows é um elemento central da experiência musical. Ela é uma espécie de texto e define um processo social e comunicacional cujas ações ritualizadas (PINCH; BIJSTERVELD, 2004) necessitam

Ver videoclipe em http://www.youtube.com/watch?v=HyHNuVaZJ-k\&feature=fvst. Acessado em 11 de abril de 2010. 
de determinados elementos socialmente construídos para produzirem sentido, como um artista desenvolvendo uma ação pré-definida - cantando, dançando, tocando - e um público que responda positivamente ou não ao comportamento desse artista. A performance ao vivo é um espetáculo (DAYAN; KATZ, 1983) cuja interação é evidente mas, comparada a outras manifestações coletivas como a festa, reduzida. Os atores - banda e plateia - se apresentam espacial e simbolicamente separados e a maior parte das ações de ambos aparece definida desde o início. É claro que tanto a banda quanto o público podem atuar de forma imprevista (a banda pode interromper 0 espetáculo, a plateia pode abandonar o show, por exemplo), mas é perfeitamente possível que a maior parte das ações seja planejada. A possibilidade de preparar e prever os principais acontecimentos da performance musical permite que 0 Gorillaz dê conta dessa experiência e, assim, legitime ainda mais a sua própria existência no mundo concreto. Os shows são minuciosamente planejados e sempre contam com a presença animada dos integrantes, o que só pode ser feito desenhando-se a performance antes que ela ocorra.

A banda faz dois tipos de shows ao vivo, que devem ser analisados separadamente. Ambos, como todas as características da música massiva que o grupo desenvolve, são feitos de maneira bastante particular.

\section{A primeira performance do Gorillaz: mistura de identidades}

Desde 0 lançamento do primeiro álbum, "Gorillaz", a performance ao vivo do grupo mistura elementos concretos - os criadores -, com virtuais - a banda -, mas sempre enfatizando a existência deste último. 0s criadores do Gorillaz e demais músicos tocam no palco, mas seus corpos ficam atrás de uma tela gigante, de forma que 0 público só vê a silhueta de cada um, não sendo possível distinguir ninguém. Enquanto isso, no meio do palco, um telão mostra imagens com animações dos integrantes do grupo tocando, cantando e, vez ou outra, mandando mensagens para a plateia. Nesse sentido, criou-se um ambiente performático em que se legitimam os criadores, visto que eles explicitamente fazem parte do show, e também os integrantes virtuais, misturando a identidade do grupo (quem é a banda, a que toca de verdade no palco ou a que aparece no telão?) de forma mais expressiva que nos ambientes virtuais já descritos. Nesse conflito constante entre 0 real e 0 virtual que o Gorillaz realiza no palco, é comum aparecer mais uma peça: como as músicas do grupo são repletas de participações especiais de músicos de carne e osso, estes costumam fazer parte do show, dividindo espaço no palco com 0 telão onde 0 Gorillaz está e dando, com isso, mais concretude e originalidade à performance. 
Como bem pontuam Janotti (2006) e Pinch e

Bijsterveld (2004), a performance das bandas que são rotuladas no gênero rock tem forte relação com a noção de originalidade. Entre outras funções, seus shows devem mostrar o virtuosismo dos instrumentistas, o desempenho do vocalista e um comportamento geral da banda que preencha as expectativas previamente construídas em torno dela. 0 Gorillaz, nesse sentido, quebra em parte esse formato; sua performance expõe os instrumentistas "originais", mas de uma maneira limitada. E essa ação é perfeitamente reconhecida e aceita pelo público.

\section{A segunda performance: o Gorillaz quase de carne e osso}

Em 2005, a plateia e os telespectadores que acompanhavam o MTV Europe Music Awards ${ }^{12}$, que ocorria ao vivo em Lisboa, tiveram uma surpresa. As cortinas do palco se abriram e, do lado esquerdo, o vocalista 2D surgiu caminhando. Do lado direito e apenas de cueca, chapéu e uma capa, o baixista Murdoc se levantou do chão, mostrou a língua para o público e começou a tocar os acordes de Feel Good Inc. No meio do palco, na parte superior, foi a vez do baterista grandão Russel. Eles tocaram a música sozinhos até o De La Soul aparecer e cantar a parte rap da canção. Enquanto os rappers se apresentavam,
2D tirou um celular do bolso e escreveu uma mensagem. Momentos depois, quando um solo de violão estava prestes a começar, a pequena Noodle apareceu calmamente, sentou-se em um banco já localizado no centro do palco e começou a tocar. Um ano depois, durante 0 Grammy Awards, a banda se apresentou da mesma maneira, dessa vez dividindo o palco com o De La Soul e, também, com Madonna. Desta vez, inclusive, parte da performance de Madonna foi feita em animação, como se ela também fosse virtual. Utilizando o sistema Musion Eyeliner ${ }^{13}$, pela primeira vez na história uma banda virtual se apresenta literalmente ao vivo. 0 Gorillaz toma forma, desenvolve toda a performance e assim oferece uma maneira totalmente nova de se apresentar ao vivo.

Antes de analisar essa performance, é necessário fazer algumas observações, pois apesar de haver um público junto ao palco e toda uma estrutura de show ao vivo, trata-se de um evento mediado pela televisão. Banda e público estão ali organizados em boa medida para serem televisionados. Essa transposição não faz com que 0 evento original seja apenas representado, ele na verdade é "utilizado como ponto de partida do evento televisionado, adapta-se a esta função, se recontextualiza, torna-se uma estrutura transitória, uma espécie de pré-imagem" (DAYAN; KATZ, 1983,

Premiação anual que a MTV concede aos videoclipes e às bandas na Europa. Criado em 1994, a cada ano acontece em uma cidade europeia diferente. 


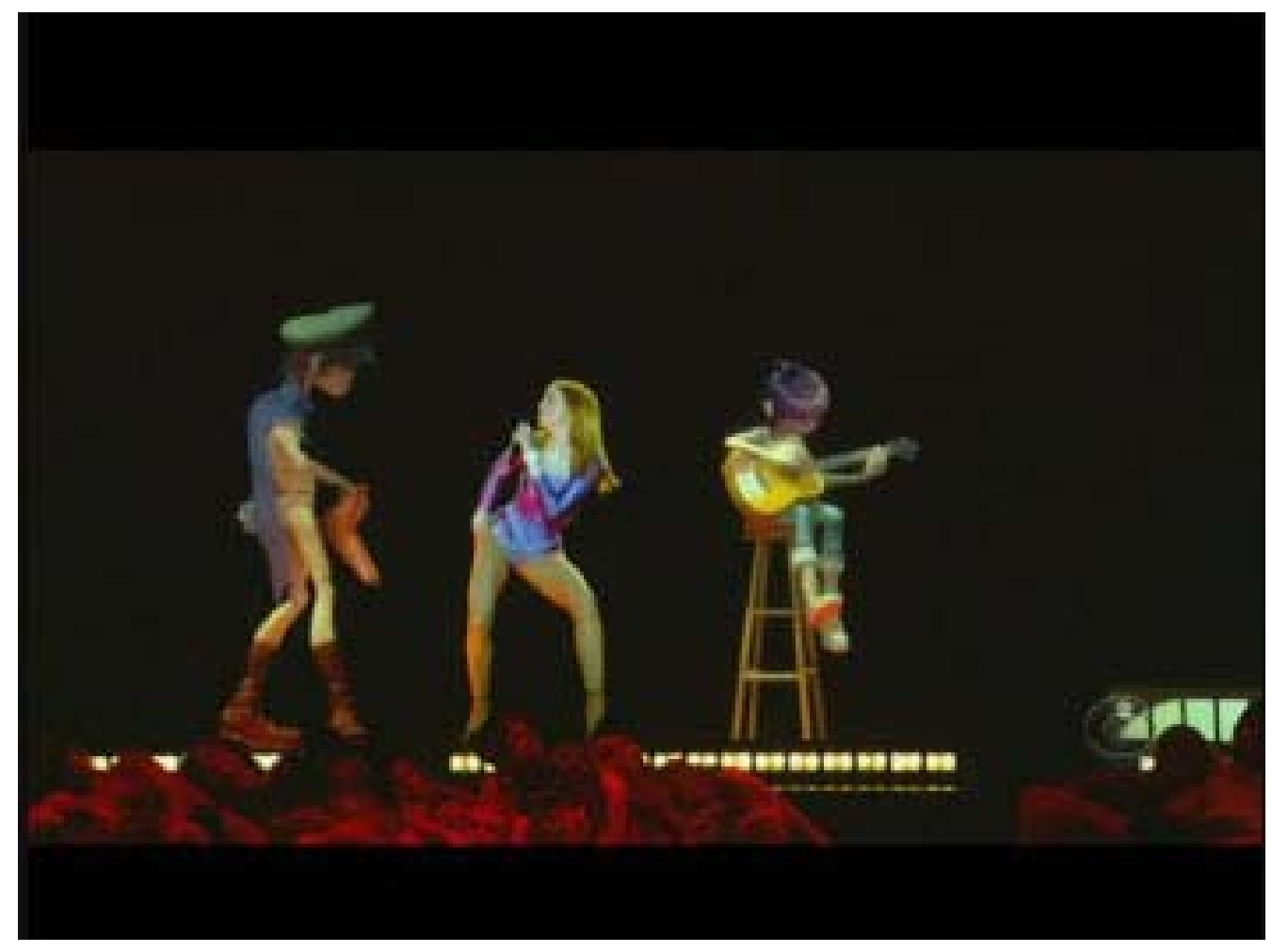

Gorillaz com o De La Soul

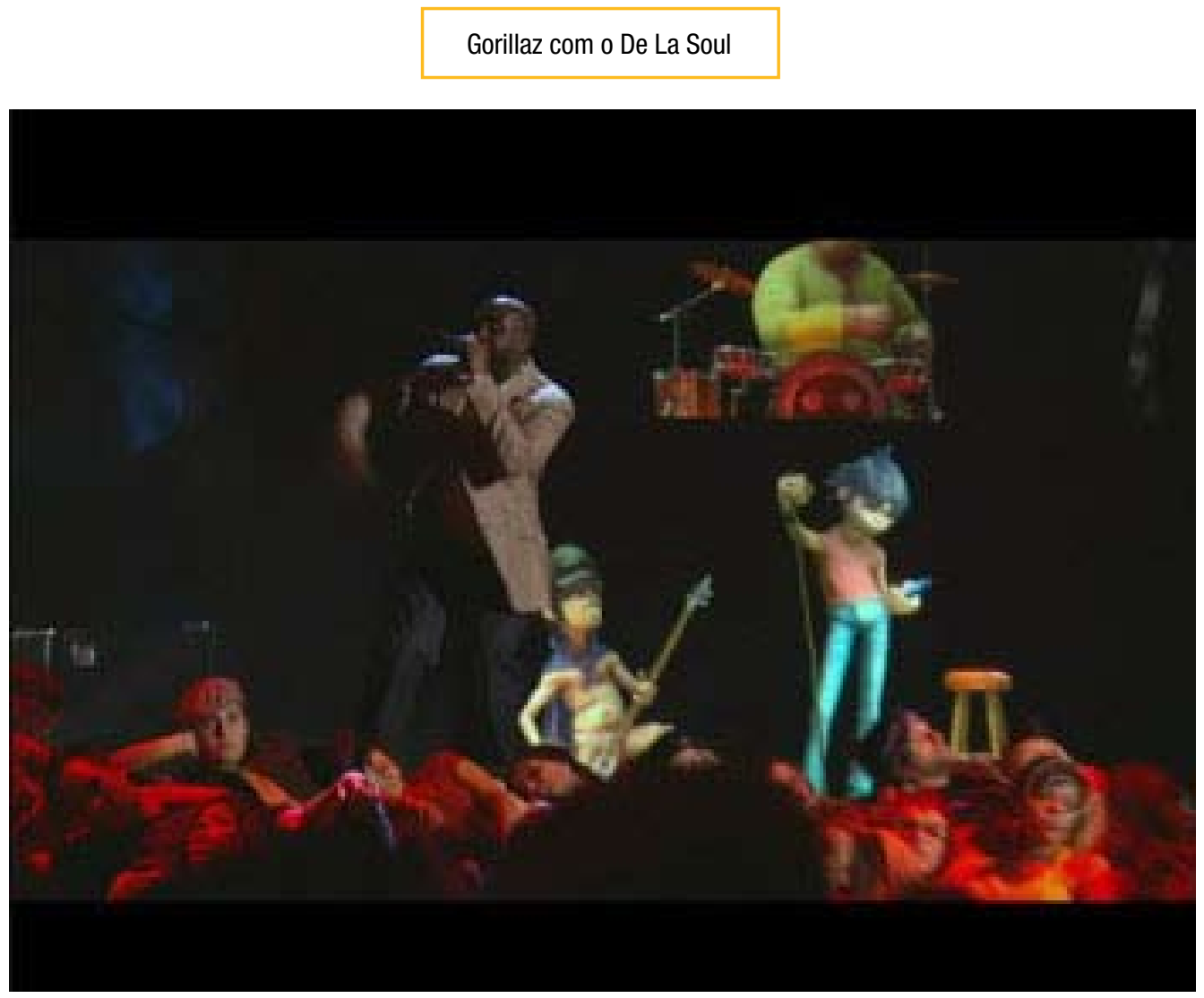


p. 2). Dessa forma, é importante entender que a

performance continua sendo performance, embora com contornos diferentes.

Misturando animação tridimensional com performers reais, essa apresentação do Gorillaz desconstrói a noção que se tem do termo. Em primeiro lugar, como afirma Frith (1996), a performance ao vivo é uma situação em que 0 pensar e 0 agir são simultâneos, trata-se de um momento em que o planejamento e 0 improviso convivem lado a lado. Em ambas as apresentações descritas, diferentemente, todas as ações do Gorillaz foram anteriormente planejadas; não há improviso. Este elemento vai aparecer de forma diferente, pois apenas os atores reais, De La Soul e Madonna, ficam responsáveis por isso. Tratase de um espetáculo com um nível de controle superior ao das performances de música massiva tradicionais, especialmente pelo fato de em muitos momentos o Gorillaz aparecer sozinho no palco, sem nenhum elemento real que possibilite o improviso. Outro elemento fundamental da performance é a linguagem corporal de quem está no palco. Em muitas performances, especialmente no rock, esse elemento tem um alto nível de interação; 0 corpo do performer "é sujeito a um tipo de controle externo, de motivação fornecida por uma pontuação, um roteiro ou uma situação social ritualizada" (FRITH, 1996, p. 206). 0 Gorillaz tem uma linguagem corporal própria, mas visto que se trata de uma apresentação inteiramente planejada, esse controle externo não acontece; apenas nos momentos em que há artistas reais em cena.
Por fim, é interessante observar que, diferentemente do que ocorre com a performance descrita anteriormente, quando os músicos reais tocam por trás de uma tela no palco, nesta eles não aparecem em nenhum momento. No lugar de ocorrer uma mistura de identidades entre os músicos reais e a banda virtual, optou-se por apagar a identidade real e priorizar apenas a virtual.

\section{Conclusão}

As bandas virtuais são um fenômeno cultural intrigante. Elas integram o circuito de música popular massiva com a mesma legitimidade que bandas não virtuais: criam álbuns, fazem shows e há um público que compra e ouve seus discos. Todavia, esse mesmo circuito tem como referência o fato de essas bandas serem inteira e explicitamente construídas, inventadas, "de mentira", apesar de haver artistas concretos por trás dessa construção. Nesse sentido, tendo como base 0 Gorillaz, este trabalhou tentou compreender como as bandas virtuais conseguem essa legitimidade e que estratégias são construídas nesse processo.

Para tanto, levando-se em conta que, para compreensão da lógica da música popular massiva é imprescindível prestar atenção, na mesma medida, nos elementos visuais e sonoros que formam essa experiência musical, a banda foi analisada por meio da construção da identidade visual e da performance musical ao vivo. No que concerne à identidade visual, 
os criadores do Gorillaz montaram uma ampla estratégia de divulgação - sites, documentário, biografia, episódios animados, entre outros - que, junto com as músicas do grupo, concedem uma identidade extremamente complexa de cada integrante, mas, ao mesmo tempo, fixa e linear. Isso ocorre porque, como as identidades foram totalmente criadas, elas dependem do suporte visual em um plano superior ao das bandas não virtuais tanto para serem mais facilmente assimiladas pelo público quanto para dar forma e sentido a elas. Tendo isso em vista, sem os videoclipes, os episódios animados e demais construções imagéticas, o Gorillaz careceria de uma identidade, pois seus integrantes não teriam uma forma, não desempenhariam ações, não teriam características que os particularizassem. A legitimidade e a manutenção da banda enquanto produto cultural passam necessariamente pela identidade visual que é construída para ela.

Já a performance ao vivo atua de maneira diferente. Como se trata de uma experiência essencialmente calcada no corpo (FRITH, 1996) - tanto no corpo de quem está no palco (seus gestos, suas danças) quanto no da platéia - é necessário então desconstruir a noção de performance para que 0 Gorillaz dê conta dessa experiência. No caso da performance em que aparecem os criadores do grupo, é montado um conflito entre o concreto - os criadores do Gorillaz, os grupos que cantam ao vivo com ele - e 0 virtual, dando-se ênfase sempre ao virtual. Além disso, os criadores aparecem escondidos, sem rosto, tornando-se quase tão virtuais quanto a sua cria. Já na segunda performance, a televisionada, os criadores são completamente apagados e a banda, mais do que nunca, ganha contornos reais. Aqui, o apagamento do referente físico concreto dos criadores contribui para ressaltar a importância dos laços de relacionamento na construção da identidade visual da banda. E esses laços já estão sendo constantemente refinados nas diversas estratégias visuais, como os videoclipes.

É claro que nessa tentativa de dar vida a 2D, Murdoc, Russel e Noodle, todos os envolvidos no processo de produção, circulação e consumo do trabalho do Gorillaz sabem que se trata de uma banda com personagens inventados e que as performances e estratégias de divulgação nada mais são do que peças para dar legitimidade, visibilidade e vendas ao grupo. Mas ocultar essas informações otimiza o processo de reconhecimento e o consumo desse tipo de banda. E serve também para pensar a constituição dos grupos de música massiva de maneira geral. Partindo do Gorillaz, como o conceito de "banda" pode ser definido? Mais do que um conjunto de pessoas tocando instrumentos, uma banda pode ser definida como um circuito comunicacional que une personagens - que não precisam necessariamente ser pessoas de carne e osso - a uma rede comunicativa formada por shows, discos, público e todo 0 circuito de produção, circulação e consumo do que é produzido por esses personagens. Olhando 
por esse ângulo, o Gorillaz seria exatamente igual a uma banda "de verdade".

\section{Referências}

ALLAN, Blaine. Musical cinema, music video, music television. Film Quarterly, Berkeley, v. 43, n. 3, p. 2-14, 1990.

BANNISTER, Matthew. 'Loaded': indie guitar rock, canonism, white masculinities. Popular Music, Cambridge, v. 25, n. 1. Cambridge University Press, 2006.

BERCHMANS, Tony. A música do filme: tudo o que você gostaria de saber sobre a música de cinema. São Paulo: Escritura, 2006.

BOORSTIN, Daniel J. The image: a guide to pseudo events in America. New York: Atheneum, 1987.

DAYAN, Daniel ; KATZ, Elihu. La télévision et la rhétorique des grandes cérémonies. In: FERR0, M. (ed.). Film et histoire. Paris: Ed. de l'École des Hautes Études, 1984. p.83-97.

FRITH, Simon. Performing rites: on the value of popular music. Massachussets: Harvard University Press, 1996.

G00DWIN, Andrew. Dancing in the distraction factory. Minneapolis: University of Minnesota Press, 1993.

HALL, Stuart. A identidade cultural na pós-

modernidade. 7. ed. Rio de Janeiro: DP\&A, 2002.

HARVEY, David. Condição pós-moderna. São Paulo: Loyola, 1992.

JAMESON, Fredric. Pós-modernismo: a lógica cultural do capitalismo tardio. São Paulo: Ática, 1996.

JANOTTI JUNIOR, Jeder S. Música popular massiva e gêneros musicais: produção e consumo da canção na mídia. Comunicação, Mídia e Consumo, São Paulo, v. 3, p. 31-48, 2006.
Música popular massiva e comunicação: um universo particular. Interin, Tuiuti, v. 4, p. 1-12, 2007.

KAPLAN, E. Ann. 0 mal estar no pós-modernismo: teorias, práticas. Rio de Janeiro: Jorge Zahar, 1993.

PINCH, Trevor; BIJSTERVELD, Karin. Sound studies: new technologies and music. Social Studies of Science, London, v. 34, n. 5 [Special issue on sound studies: new technologies and music], p. 635-648, 2004.

SANTAELLA, Lúcia. Cultura das mídias. São Paulo: Experimento, 2000.

STERNE, Jonathan. The audible past: cultural origins of sound reproduction. Durham: Duke University Press, 2003. 
Is Gorillaz a fake band? A discussion about the role of virtual bands in pop music

\section{¿Gorillaz es una banda de verdad? Una discusión sobre el papel de las bandas virtuales en la música pop}

\section{Abstract}

This paper will discuss the role of virtual bands in pop music today in order to understand how a band that does not exist in the "real world" is part of the entertainment industry with the same legitimacy as bands with real members. To do this, this paper will analyze the Gorillaz's live performances and some of its consolidation strategies. Gorillaz is one of the most striking of this kind in many decades. To have legitimacy and be able to fit in the music scene, these bands modify some essential elements of the musical experience, deconstructing part of their concepts.

\section{Keywords}

Virtual band. Pop Music.

Visual strategies. Performance.

\section{Resumen}

Este artículo tiene por objeto un debate sobre el papel de las bandas virtuales en la música pop actual, a fin de comprender cómo una banda que no existe físicamente hace parte de la industria del entretenimiento con la misma legitimidad que bandas reales. Para eso, serán analizadas las actuaciones en vivo y las estrategias del surgimiento y consolidación de la banda virtual Gorillaz, una de las más notables de su tipo en décadas. Para que tengan legitimidad y se cuadren en la escena musical, estas bandas tratan de manera bastante particular elementos esenciales de la experiencia musical, con la deconstrucción de parte de sus conceptos.

\section{Palabras clave}

Banda virtual. Música pop.

Identidad visual. Performance. 


\section{Expediente}

A revista E-Compós é a publicação científica em formato eletrônico da Associação Nacional dos Programas de Pós-Graduação em Comunicação (Compós). Lançada em 2004, tem como principal finalidade difundir a produção acadêmica de pesquisadores da área de Comunicação, inseridos em instituições do Brasil e do exterior.
E-COMPÓS I www.e-compos.org.br I E-ISSN 1808-2599

Revista da Associação Nacional dos Programas de Pós-Graduação em Comunicação. Brasília, v.13, n.1, jan./abr. 2010.

A identificação das edições, a partir de 2008 passa a ser volume anual com três números.

\section{CONSELHO EDITORIAL}

Afonso Albuquerque

Universidade Federal Fluminense, Brasil

Alberto Carlos Augusto Klein

Universidade Estadual de Londrina, Brasil

Alex Fernando Teixeira Primo

Universidade Federal do Rio Grande do Sul, Brasil

Alfredo Vizeu

Universidade Federal de Pernambuco, Brasil

Ana Carolina Damboriarena Escosteguy

Pontifícia Universidade Católica do Rio Grande do Sul, Brasil

Ana Silvia Lopes Davi Médola

Universidade Estadual Paulista, Brasil

André Luiz Martins Lemos

Universidade Federal da Bahia, Brasil

Ângela Freire Prysthon

Universidade Federal de Pernambuco, Brasil

Antônio Fausto Neto

Universidade do Vale do Rio dos Sinos, Brasil

Antonio Carlos Hohlfeldt

Pontifícia Universidade Católica do Rio Grande do Sul, Brasil

Arlindo Ribeiro Machado

Universidade de São Paulo, Brasil

César Geraldo Guimarães

Universidade Federal de Minas Gerais, Brasil

Cristiane Freitas Gutfreind

Pontifícia Universidade Católica do Rio Grande do Sul, Brasil

Denilson Lopes

Universidade Federal do Rio de Janeiro, Brasil

Eduardo Peñuela Cañizal

Universidade Paulista, Brasil

Erick Felinto de Oliveira

Universidade do Estado do Rio de Janeiro, Brasil

Francisco Menezes Martins

Universidade Tuiuti do Paraná, Brasil

Gelson Santana

Universidade Anhembi/Morumbi, Brasil

Goiamérico Felício

Universidade Federal de Goiás, Brasil

Hector Ospina

Universidad de Manizales, Colômbia

Herom Vargas

Universidade Municipal de São Caetano do Sul, Brasil

leda Tucherman

Universidade Federal do Rio de Janeiro, Brasil

Itania Maria Mota Gomes

Universidade Federal da Bahia, Brasil

Janice Caiafa

Universidade Federal do Rio de Janeiro, Brasil

Jeder Silveira Janotti Junior

Universidade Federal da Bahia, Brasil
João Freire Filho

Universidade Federal do Rio de Janeiro, Brasil

John DH Downing

University of Texas at Austin, Estados Unidos

José Luiz Aidar Prado

Pontifícia Universidade Católica de São Paulo, Brasil

José Luiz Warren Jardim Gomes Braga

Universidade do Vale do Rio dos Sinos, Brasil

Juremir Machado da Silva

Pontifícia Universidade Católica do Rio Grande do Sul, Brasil

Lorraine Leu

University of Bristol, Grã-Bretanha

Luiz Claudio Martino

Universidade de Brasília, Brasil

Maria Immacolata Vassallo de Lopes

Universidade de São Paulo, Brasil

Maria Lucia Santaella

Pontifícia Universidade Católica de São Paulo, Brasil

Mauro Pereira Porto

Tulane University, Estados Unidos

Muniz Sodre de Araujo Cabra

Universidade Federal do Rio de Janeiro, Brasil

Nilda Aparecida Jacks

Universidade Federal do Rio Grande do Sul, Brasil

Paulo Roberto Gibaldi Vaz

Universidade Federal do Rio de Janeiro, Brasil

Renato Cordeiro Gomes

Pontifícia Universidade Católica do Rio de Janeiro, Brasil

Ronaldo George Helal

Universidade do Estado do Rio de Janeiro, Brasil

Rosana de Lima Soares

Universidade de São Paulo, Brasil

Rossana Reguillo

Instituto Tecnológico y de Estudios Superiores do Occidente, México

Rousiley Celi Moreira Maia

Universidade Federal de Minas Gerais, Brasil

Samuel Paiva

Universidade Federal de São Carlos, Brasil

Sebastião Albano

Universidade Federal do Rio Grande do Norte, Brasil

Sebastião Carlos de Morais Squirra

Universidade Metodista de São Paulo, Brasil

Simone Maria Andrade Pereira de Sá

Universidade Federal Fluminense, Brasil

Suzete Venturelli

Universidade de Brasília, Brasil

Valério Cruz Brittos

Universidade do Vale do Rio dos Sinos, Brasil

Veneza Mayora Ronsini

Universidade Federal de Santa Maria, Brasil

Vera Regina Veiga França

Universidade Federal de Minas Gerais, Brasil

\section{COMISSÃO EDITORIAL}

Felipe da Costa Trotta I Universidade Federal de Pernambuco, Brasil Rose Melo Rocha I Escola Superior de Propaganda e Marketing, Brasil CONSULTORES AD HOC

João Maia I Universidade do Estado do Rio de Janeiro, Brasil Sandra Gonçalves I Universidade Federal do Rio Grande do Sul, Brasil Mayra Rodrigues Gomes I Universidade de São Paulo, Brasil Gisela Castro I Escola Superior de Propaganda e Marketing, Brasil João Carrascoza I Escola Superior de Propaganda e Marketing, Brasil Luciana Pellin Mielniczuk I Universidade Federal de Santa Maria, Brasil Irene de Araújo Machado I Universidade de São Paulo, Brasil Hermilio Pereira dos Santos Filho I Pontifícia Universidade Católica, Brasil Benjamim Picado I Universidade Federal Fluminense, Brasil Maria Apaecida Baccega I Escola Superior de Propaganda e Marketing, Brasil Rogério Ferraraz I Universidade Anhembi Morumbi, Brasil

Bruno Souza Leal I Universidade Federal de Minas Gerais, Brasi REVISÃO DE TEXTO E TRADUÇÃo I Everton Cardoso EDITORAÇ̃̃ ELETRÔNICA I Roka Estúdio
COMPóS I www.compos.org.br

Associação Nacional dos Programas de Pós-Graduação em Comunicação

Presidente

Itania Maria Mota Gomes

Universidade Federal da Bahia, Brasil

itania@ufba.br

Vice-presidente

Julio Pinto

Pontifícia Universidade Católica de Minas Gerais, Brasil juliopinto@pucminas.br

Secretária-Geral

Ana Carolina Escosteguy

Pontifícia Universidade Católica do Rio Grande do Sul, Brasil carolad@pucrs.br 